\title{
Papers
}

\section{Comparing prompted and unprompted methods for measuring consumer brand associations}

Received (in revised form): 25th September, 2006

\section{Jenni Romaniuk}

heads the Brand Equity Research Program at the Ehrenberg-Bass Institute for Marketing Science, based at the University of South Australia. Her areas of research expertise are in brand salience; providing context and meaning brand equity tracking results and detecting the effectiveness of marketing activities. She is also Editor of the Journal of Empirical Generalisations in Marketing.

\begin{abstract}
A common method used to measure brand associations is a free choice, 'pick any' approach. This is where a battery of attributes is provided and consumers are asked which brands they associate with each attribute. One issue that arises using this method is whether to prompt for brand names or ask people to recall brands. In tests across two different markets, it was evident that while the brand ranks for prompting or not prompting were similar, an unprompted approach was less likely to elicit associations from nonbrand users and smaller share brands. Unprompted methods were also more prone to priming and inhibition effects over the duration of the attribute battery. Therefore, using an unprompted approach will risk under-reporting consumer knowledge structures from these lower accessibility groups. This is problematic for marketing managers seeking to monitor smaller share brands and particularly new entrants into a marketplace, as well as for those seeking to grow via acquisition of nonbrand users. Journal of Targeting, Measurement and Analysis for Marketing (2006) 15, 3-11. doi:10.1057/palgrave.jt.5750029
\end{abstract}

\section{INTRODUCTION}

Information encountered during brand experiences, which may be buying, consuming, viewing the brand's advertising or engaging in word of mouth can, if processed, become linked to the brand name in buyer memory. Brand associations are the results of this processing. These are the concepts linked to the brand name in consumer memory. ${ }^{1}$ These associations have many uses, including being components of the overall brand attitude or to access brands from memory for further information processing. ${ }^{2-4}$ As a result, most brand health tracking instruments include a section that

Correspondence: Jenni Romaniuk, Senior Research Fellow,

Ehrenberg-Bass Institute for Marketing Science, University of South

Australia, PO Box 2471, Adelaide, South Australia 5001, Australia.

Tel: + 6188302 0706;

Fax: +6129475 0203;

E-mail: Jenni.Romaniuk@Marketingscience.info measures the associations that consumers hold for competitive brands in a market.

One of the most popular approaches for capturing the brand associations held by consumers is via a free choice, 'pick any' method. In this approach, brand attributes (such as good value or low fat) are provided to respondents who are asked to indicate which, if any, brands they associated with each attribute. ${ }^{5}$ One decision that needs to be made when adopting this type of measure is whether to provide respondents with a set of brands (prompting for brands), or have them elicit brands from memory (unprompted). While some have argued that unprompted methods are more appropriate in certain categories, there are other issues such as priming, inhibition effects that may lead to underreporting of brand associations, particularly for less accessible associations such as those for small 
brands or for nonbrand users. While there have been several studies that have compared the results for a free choice, pick any method with other possible approaches such as rating scales or ranking brands on attributes, ${ }^{5,6}$ the technical aspects within specific measures (particularly a free choice, pick any approach) have received less academic attention.

While it might seem that the decision to prompt or not might only arise in certain situations, this issue is becoming even more relevant with the growth in the number of brands in most categories. This means that the list of possible competitors is often longer than can practically be provided to survey respondents. A movement to a methodology where brands are not prompted becomes more attractive as it removes the requirement to decide which brands to include in brand lists. This makes the difference between the consumer associations elicited in brand prompted and unprompted methodologies of interest to marketers in most categories.

The aim of this research is therefore to compare the nature of brand associations elicited unprompted with those elicited when consumers are prompted for brands. The objective is to determine if there are meaningful differences that would lead one method to be preferable over the other under any specific conditions.

\section{BACKGROUND}

There have not been any studies that have specifically examined this issue from the perspective of brand associations. This is most likely because most of the academic research into brand associations has focussed on measurement using rating scales. In the advertising and brand awareness literature, however, there has been considerable debate on the difference between prompted and unprompted approaches. These areas of research can be considered similar in that they involve retrieval of the brand name, but in response to category or brand cues rather than an image attribute. In the advertising awareness area, there has been considerable debate about unprompted (recall) and prompted (recognition) measures, examining both the differences and the conditions under which one is preferable over the other. ${ }^{7-10}$ Overall, there has been no general consensus except for broad agreement that response levels for prompted measures are higher and more stable over time. ${ }^{11}$

In the brand awareness literature, there has been a similar, albeit more muted debate. Again there is agreement that prompted measures produce more responses than unprompted measures. Laurent et al. ${ }^{12}$ compared three commonly used brand awareness measures (topof-mind or first brand recalled, unprompted recall and prompted recognition that the brand is a member of the category). The measures were found to follow a similar underlying structure, with the difference in response levels able to be explained by a constant that represented the degree of difficulty of the measure, with unprompted measures considered more difficult than prompted measures. Further research by Romaniuk et al., ${ }^{13}$ however, found that the relationship found by Laurent et al. was simply a reflection of market share. A large share brand will always gain more responses than a small share brand for brand awareness measure. Also any brand will gain a higher number of responses under a prompted methodology than an unprompted methodology. These two patterns combine to make the relationship observed by Laurent et al. and Romaniuk et al. When examining brands over time, however, the similarity between the measures becomes less clear, with larger share brands varying over time more on more difficult measures while small share brands varied more over time on easier measures. This means that the two types of measures might not be interchangeable.

One justification given for the awareness measure choice is the buying situation, where Percy and Rossiter ${ }^{14}$ argue that the two types of awareness (and therefore the types of measures that under pin them) are very different constructs. Lynch and Srull ${ }^{15}$ distinguish between three different types of buying situations; memory based, stimulus based and mixed (both memoryand stimulus-based) situations. If the category is one that requires consumers to retrieve brand names from memory (eg, pizza delivery), then unprompted methods are considered more 
appropriate. In contrast when the buying situation faced by consumers involves selecting from alternatives that are present (such as when selecting haircare in a supermarket); then prompted measures are more appropriate. The idea behind this being that it is best to match the measurement approach with the cognitive processes undertaken by the consumer during the choice situation. It is, however, unclear what would be preferred in a mixed scenario (the third of Lynch and Srull's categories). This is problematic given that it has been argued that most, if not all, buying situations involve some mix of the external environment as a stimulus and retrieval of information from memory. ${ }^{16}$ Even in a stimulus-based supermarket environment, very little time is spent attending to all stimulus, with an average of $12 \mathrm{~s}$ spent selecting a brand from a category, with nearly half in under $5 \mathrm{~s} .{ }^{17}$ This suggests that even in that environment, when everything is in front of the consumer, retrieval of information from memory plays an important role in the choice process. Therefore, while some categories might lean towards more memory or more stimuli based, all categories may have sufficient mix of both to be indistinguishable from the perspective of measuring brand associations. If the consumer choice situation influences measurement, then the patterns of responses for brand across markets should differ in different markets that traditionally fall under the differing Lynch and Srull categorisations. If, however, both rely on both memory and stimulus, the pattern of responses will be highly similar in both types of markets.

\section{PRIMING AND RECENCY EFFECTS}

While some similarities can be drawn between Brand/Advertising awareness measures and brand association measures, there is one important difference that may mean the findings from awareness research might not extend to this similar context. Brand and advertising awareness measures typically involve only one instance of brand retrieval with the product category/brand as the retrieval cue. In contrast, brand associations are measured via a battery of attributes, where over 20 different ones are not unusual. A key difference between prompted and unprompted methodologies is the requirement, when brands are not prompted, for the consumer to recall brand names from long-term memory. The act of recall moves a brand from long-term memory into working memory for further cognitive processing. Working memory has well-established limitations in capacity, which restricts the number of items that can be held. ${ }^{18}$ Further the presence of brands in working memory can inhibit the retrieval of other brands even when the consumer is actively trying to recall as many as possible. ${ }^{19,20}$ Therefore, measuring brand associations unprompted might reduce the number of brands that are retrieved as the respondent goes through the list. This may lead to an under-representation of brand associations in unprompted methodologies as working memory fills up with options and the ease of retrieval of additional items declines. If it is due to the filling up of working memory inhibiting other brands from being retrieved, the effect should be greater in the later attributes than in earlier attributes (eg, the last ten in a battery of 20).

The other issue of inhibition effects is that it might penalise some sub-groups of the less accessible brand associations. Two such sub-groups of associations are those provided by nonbrand users and those for smaller share brands. Brand usage is well known to have an effect on the propensity to give any brand associations, ${ }^{21,22}$ but marketers are still interested in measuring and understanding the brand associations held by nonbrand users. Given that the first brands that are likely to be retrieved by a consumer are those that they currently use, it might be that brands not used are unduly penalised in an unprompted methodology. Similarly small share brands are in a situation that for the initial retrieval instances, larger share brands are more likely to be accessible than smaller share brands. Therefore, smaller share brands have a lower chance to be retrieved for the first attributes and this should decrease even further as working memory becomes 'full'. It might be expected that brand associations given by nonusers and brand associations given for smaller share brands will be disproportionately lower than comparative results 
for associations given by brand users and for larger share brands.

\section{RESEARCH HYPOTHESES}

This leads to the following hypotheses:

$\mathbf{H}_{1}$ : If unprompted and prompted methodologies are drawing on the same construct, then the brand response levels for an attribute when prompted for brands should be able to be estimated from the unprompted response levels for the same brand on the same attributes (and vice versa).

$\mathbf{H}_{2}$ : The difference in the number of brands generated by an unprompted versus a prompted method will be greater for attributes presented later in an attribute battery.

$\mathbf{H}_{3}$ : Unprompted methodologies will generate disproportionately fewer responses from nonbrand users than prompted methodologies.

$\mathbf{H}_{4}$ : Unprompted methodologies will penalise smaller share brands more than larger share brands

$\mathbf{H}_{5}$ : If the consumer choice situation is important determinant in deciding whether to measure brand associations via an unprompted or prompted methodology, then the relationships will differ for categories that represent either memory or stimulus dominant buying situations.

\section{RESEARCH METHOD}

The research included two categories of Toothpaste and Insurance. These categories were chosen based on being relative extremes in consumer choice situations, while still being normal everyday categories that most people encounter. The stimulus-based condition covered brands in the Toothpaste category, while the memory-based condition was brands in the Insurance category. A split sample methodology was used where 199 respondents were randomly split into two groups. The first group $(n=110)$ were prompted for insurance brands, but not for toothpaste brands. The second group $(n=89)$ were prompted for toothpaste brands but not insurance brands.

Respondents were asked which brands they associated with a list of 16 attributes for each category, which were derived from prior experience with each category, category benefits and observation of advertised messages and product claims. The order of the attributes in the questionnaire was randomly derived. In Toothpaste, 12 brands were analysed, while for Insurance nine brands were included in the research.

As expected, based on prior research, the prompted scenarios did also elicit more brands overall (see Table 1), with the prompted scenarios eliciting 2.0 and 1.3 responses on average, compared to 1.3 and 0.9 in the equivalent unprompted scenarios. There were some specific attributes where there were no differences. These were all attributes with a lower mean number of brands (1.2 brands or below), however, this was not a characteristic of all low mean attributes. In Insurance the attributes were cover all needs, has a range of policies, has an efficient telephone enquiry system, help in an emergency and fast service. In toothpaste for sensitive teeth was the only attribute where there was no difference. This might suggest that for these attributes, there were so few brands linked to the attribute that there was no retrieval threshold to reach and so all brands could be retrieved in each methodology.

\section{RELATIONSHIP BETWEEN PROMPTED AND UNPROMPTED BRAND RESPONSES}

The first analysis was to compare the brand responses gained for each attribute from the prompted versus the unprompted scenario. This was analysed for each attribute individually, using single linear regression (prompted responses as the independent variable). Results shown in Table 2 
show that the responses are equivalent with Beta's generally close to 1 and adjusted $R$-squareds averaging 0.90 for toothpaste; and Adjusted $R$-squareds averaging 0.67 for Insurance. The size of the constant is directly correlated with the response level for that attribute $(0.96, p<0.001$ for toothpaste and $0.94, p<0.001$ for Insurance). The attributes that were exceptions to this were concentrated in the Insurance market, seem to be linked to some of the smaller brands not being mentioned at all when unprompted, indicating that a lack of variation was the reason for the low $R$-squared, rather than a totally different relationship between the two approaches for those attributes. Therefore, $\mathrm{H}_{1}$ is supported.

\section{PRIMING AND RECENCY EFFECTS}

To test for potential priming/inhibition effects, respondents in both methods were presented attributes in the same order. This allows the

Table 1: Average number of brand responses for each attribute

\begin{tabular}{|c|c|c|c|c|c|}
\hline Attribute & Prompt & Unprom & Attribute & Prompt & Unprom \\
\hline Offers car insurance & 2.5 & 1.7 & Fights plaque & 3.7 & 1.8 \\
\hline Home insurance & 2.0 & 1.3 & Provides protection & 3.3 & 1.9 \\
\hline Brand I can trust & 1.4 & 0.9 & Freshen breath & 2.9 & 2.0 \\
\hline Good value & 1.3 & 0.8 & Confidence & 2.7 & 1.5 \\
\hline Cover all needs & 1.2 & 1.2 & A brand I trust & 2.2 & 1.5 \\
\hline Range of policies & 1.2 & 1.2 & Looks after gums too & 2.1 & 1.3 \\
\hline Respect & 1.2 & 1.0 & Taste great & 1.9 & 1.4 \\
\hline Socially responsible & 1.2 & 0.5 & Whiten teeth & 1.8 & 1.6 \\
\hline Treat me well & 1.1 & 0.9 & Great value for money & 1.8 & 1.2 \\
\hline Efficient telephone & 1.1 & 1.1 & New innovations & 1.7 & 0.9 \\
\hline Conv. located branches & 1.0 & 0.5 & Sensitive teeth & 1.1 & 1.1 \\
\hline Help in an emergency & 1.0 & 1.0 & Option for kids & 1.0 & 0.9 \\
\hline Keeps me informed & 0.9 & 0.5 & Contains mouthwash & 1.0 & 0.6 \\
\hline Fast service & 0.8 & 0.8 & Pump style options & 0.7 & 0.6 \\
\hline Average & 1.3 & 0.9 & Average & 2.0 & 1.3 \\
\hline
\end{tabular}

Table 2: Attribute regression results

\begin{tabular}{|c|c|c|c|c|c|c|c|c|c|}
\hline Attribute & $\begin{array}{l}\text { Adj } \\
R \text {-square }\end{array}$ & Beta & C & Ave RL & Attribute & $\begin{array}{l}\text { Adj } \\
R \text {-square }\end{array}$ & Beta & C & $\begin{array}{l}\text { Ave } \\
\text { RL }\end{array}$ \\
\hline Fights plaque & $0.92^{*}$ & 1.0 & 17 & 30 & Help in emergency & $0.90^{*}$ & 1.0 & 9 & 20 \\
\hline Freshen breath & $0.78^{*}$ & 0.9 & 12 & 25 & $\begin{array}{l}\text { Offers car } \\
\text { insurance }\end{array}$ & $0.85^{\star}$ & 0.9 & 27 & 47 \\
\hline Reduces tartar & $0.89^{*}$ & 0.9 & 13 & 23 & $\begin{array}{l}\text { Offers home } \\
\text { insurance }\end{array}$ & $0.85^{\star}$ & 0.9 & 40 & 52 \\
\hline Confidence & $0.95^{\star}$ & 1.0 & 11 & 21 & Respect & $0.84^{*}$ & 0.9 & 7 & 18 \\
\hline A brand I trust & $0.95^{\star}$ & 1.0 & 6 & 20 & Range of policies & $0.78^{\star}$ & 0.9 & 38 & 48 \\
\hline Looks after gums & $0.91^{*}$ & 1.0 & 7 & 19 & $\begin{array}{l}\text { Conv. located } \\
\text { branches }\end{array}$ & $0.75^{\star}$ & 0.9 & -2 & 10 \\
\hline Taste great & $0.96^{*}$ & 1.0 & 7 & 19 & Would treat me & $0.72^{*}$ & 0.9 & 11 & 21 \\
\hline Whiten teeth & $0.80^{*}$ & 0.9 & 4 & 15 & Can cover all & $0.72^{*}$ & 0.9 & 27 & 37 \\
\hline New innovations & $0.95^{\star}$ & 1.0 & 6 & 14 & Trust & $0.71^{\star}$ & 0.9 & 1 & 19 \\
\hline Great value & $0.91^{*}$ & 1.0 & 3 & 13 & Easy to under & $0.57^{\star}$ & 0.8 & 7 & 11 \\
\hline Option for kids & $0.99^{\star}$ & 1.0 & 1 & 9 & Good value & $0.53^{\star}$ & 0.8 & 1 & 16 \\
\hline Mouthwash & $0.61^{*}$ & 0.8 & 1 & 9 & Fast service & $0.41^{*}$ & 0.7 & 11 & 15 \\
\hline Pump style options & $1.00^{*}$ & 1.0 & 0 & 6 & Complete cover & $0.40^{\star}$ & 0.7 & 20 & 31 \\
\hline Fun & $0.93^{*}$ & 1.0 & 0 & 5 & Socially responsible & 0.24 & 0.6 & 17 & 22 \\
\hline Average & 0.90 & 1.0 & 7 & 17 & Average & 0.67 & 0.8 & 15 & 26 \\
\hline
\end{tabular}

${ }^{\star} p<0.05$. 
ability to compare responses for earlier attributes with that for later attributes. The analysis compared the number of brands mentioned for each attribute to determine if the gap between prompted and unprompted methods is higher for latter attributes. The attributes were split into four groups of four, based on order of presentation. The percentage difference was calculated by dividing the difference between prompted and unprompted methods by the number of brands elicited prompted. The results (shown in Table 3) suggest different patterns for each market. In Insurance, the average difference between prompted and unprompted declined steadily for the later attributes (48 per cent for the first 4 compared to 10 per cent for the last 4). For Toothpaste, however, the difference rose for later attributes ( 21 per cent for the first 4 to 37 per cent for the last 4). This suggests that for Insurance, when unprompted the subsequent attributes access accumulates brands into working memory to make more brands accessible for later attributes. This suggests that with an unprompted methodology it is not that later attributes are inhibited, but that the harder initial retrieval means that fewer brands are accessed for early attributes.

For Toothpaste the opposite pattern was evident, despite there being no change in the number of brands elicited when the methodology was prompted, there were fewer brands elicited unprompted for latter attributes. The third 4 had an average of 1.4 brands mentioned unprompted, while the last 4 had an average of 1.1 brands. Therefore, while $\mathrm{H}_{2}$ is supported for Toothpaste,

Table 3: Relationship between attribute order presentation and difference between methods

\begin{tabular}{llll}
\hline & Prompted & Unprompted & $\%$ diff \\
\hline Insurance & & & \\
$\quad$ First 4 & 1.3 & 0.7 & 48 \\
$\quad$ Second 4 & 1.5 & 1.1 & 26 \\
$\quad$ Third 4 & 1.1 & 0.9 & 18 \\
$\quad$ Last 4 & 1.3 & 1.1 & 10 \\
Toothpaste & & & \\
$\quad$ First 4 & 1.7 & 1.3 & 21 \\
Second 4 & 2.2 & 1.3 & 33 \\
$\quad$ Third 4 & 2.0 & 1.4 & 29 \\
$\quad$ Last 4 & 2.0 & 1.1 & 37 \\
\hline
\end{tabular}

but not Insurance, however, both disparities suggest that the associations generated when the measurement approach is unprompted varies over an attribute battery for an individual.

\section{BRAND NONUSERS}

To examine this issue, respondents were classified as either brand users or nonusers for each brand based on self-reported responses about which brands they used for that category. For Toothpaste, the brand usage questions were Which brands of toothpaste do you currently use? and Which brands of toothpaste have you used in the paste? to capture the full brand repertoire for an individual. For Insurance, the consumer had three opportunities to say they used the brand. Specifically, the question (asked after a category screen) was which company do you use for your car insurance? This was then repeated for Home building and Home Contents insurance. These three types of insurance were the main product categories covered by the insurance brands included in the study.

The proportion of responses from nonusers for each brand was compared for each method. Only brands with sufficient numbers of users were able to be included in this analysis, which limited the number of brands to five for toothpaste and six for insurance. The results, presented by brand in Table 4, show that unprompted methods get proportionally fewer responses from brand nonusers (about $1 / 2$ ) than generated by prompted methodologies. In contrast, there is very little difference in the number of associations from brand users by each method. This supports $\mathrm{H}_{3}$.

\section{SMALL SHARE BRANDS}

The final analysis was to determine if unprompted methodologies penalise smaller brands more than larger brands. To ascertain this, the share of market (as determined by the number of brand users) was compared to the share of associations (total proportion of brand associations). The sum for the three largest and three smallest brands was calculated in each market. The results (Table 5) show that for both markets, the results for the unprompted methodology show much more polarisation 
Table 4: Brand users versus non-users

\begin{tabular}{|c|c|c|c|c|c|c|}
\hline & \multicolumn{3}{|c|}{ Prompted methodology } & \multicolumn{3}{|c|}{ Unprompted method } \\
\hline & Nonusers & Users & NU/BU (\%) & Nonusers & Users & NU/BU (\%) \\
\hline \multicolumn{7}{|l|}{ Toothpaste } \\
\hline Colgate & 53 & 59 & 90 & 17 & 59 & 29 \\
\hline Sensodyne & 14 & 18 & 78 & 6 & 20 & 30 \\
\hline MacLeans & 21 & 35 & 60 & 7 & 34 & 21 \\
\hline AIM & 8 & 27 & 30 & 2 & 11 & 18 \\
\hline Oral B & 10 & 42 & 24 & 5 & 24 & 21 \\
\hline Average & 21 & 36 & 56 & 7 & 30 & 24 \\
\hline \multicolumn{7}{|l|}{ Insurance } \\
\hline RAA & 24 & 47 & 51 & 12 & 37 & 32 \\
\hline SGIC & 15 & 35 & 43 & 13 & 38 & 34 \\
\hline Allianz & 9 & 25 & 36 & 5 & 41 & 12 \\
\hline AAIM & 13 & 45 & 29 & 7 & 44 & 16 \\
\hline CGU & 4 & 24 & 17 & 1 & 38 & 3 \\
\hline QBE & 4 & 27 & 15 & 1 & 21 & 5 \\
\hline Average & 12 & 34 & 32 & 7 & 37 & 17 \\
\hline
\end{tabular}

Table 5: Comparisons between small and large share brands

\begin{tabular}{|c|c|c|c|}
\hline & \multirow{2}{*}{$\begin{array}{l}\text { Share of } \\
\text { market }\end{array}$} & \multicolumn{2}{|c|}{ Share of associations } \\
\hline & & Prompted & Unprompted \\
\hline \multicolumn{4}{|l|}{ Toothpaste } \\
\hline $\begin{array}{l}\text { Three largest } \\
\text { brands }\end{array}$ & 80 & 52 & 70 \\
\hline $\begin{array}{l}\text { Three smallest } \\
\text { brands }\end{array}$ & 1 & 10 & 5 \\
\hline \multicolumn{4}{|l|}{ Insurance } \\
\hline $\begin{array}{l}\text { Three largest } \\
\text { brands }\end{array}$ & 56 & 53 & 59 \\
\hline $\begin{array}{l}\text { Three smallest } \\
\text { brands }\end{array}$ & 7 & 12 & 4 \\
\hline
\end{tabular}

between large and small brands (14 times versus 5 times for prompted for Toothpaste and eight times versus four times for Insurance).

\section{CATEGORY COMPARISONS}

In order to draw some conclusions about the relationship between the choice situation and the type of measurement approach best used, two different categories were included in the research. Toothpaste was selected as a typical stimulusbased category, with most choice situations in a supermarket (or equivalent) setting with all stimuli in front of the consumer. Insurance was chosen as a category where people have to typically retrieve brand names from memory to further follow up in choice situations. The results show that generally the relationship between prompted and unprompted responses was the same for both categories, with statistically significant and similar results from both. The brand user/nonuser analysis revealed the same types of patterns across categories. Nonusers were about 50 per cent less likely to give brand associations when not prompted while brand users varied little. While the small and large brand comparison revealed a similar under-representation of small brands when brands were not prompted, although this was more extreme for Insurance than for Toothpaste.

A difference did emerge when examining the effect of presenting attributes over time when an unprompted method was used. For toothpaste, the expected pattern of inhibition for later attributes was evident, with the prompted versus unprompted gap between the number of brands mentioned for attributes widening. While for Insurance, the difficultly of accessing brands when not prompted meant that after more attributes, more brands were accessible. This reduced the prompted versus unprompted gap in the number of brands per attribute for latter attributes. While the patterns differ, however, what was evident is 
that there were more changes for unprompted methodology that could be linked to accessibility issues such as priming or retrieval. In contrast, brand associations elicited by sub-groups when prompted seemed more stable.

\section{DISCUSSION}

The objective of this research was to compare the brand associations retrieved via a method where consumers were prompted for brands, with an alternative where consumers were required to retrieve brands unprompted. The results show a high level of agreement in the results for each approach in terms of brand ranks, such that the level of prompted brand associations can be accurately estimated knowing the level of unprompted brand association for an attribute.

But the measures are not equivalent in that an unprompted approach seems to bias more against brand nonusers retrieving brand associations and (linked to this) brand associations for smaller share brands. This means that using an unprompted methodology under-represents the brand associations that consumers have for smaller share brands. Given that new entrants to a market begin as smaller share brands, this may lead a marketer to miss out on identifying potential threats in the marketplace. The unprompted methodology also seems to be influenced by accessibility factors as the consumer progressed through the attribute battery. While randomising the presentation of attributes across consumers might dampen the effects of this, these accessibility factors are still potential confounding factors in the results. Importantly, they show that repeated unprompted measures are prone to priming and inhibition effects. Unless these are somehow eradicated, they should be of concern to anyone trying to interpret a brands' association with any one attribute.

This result was evident for both a (more) stimulus-based and a (more) memory-based choice situation, giving support to the idea that at least from the perspective of measuring brand associations, the choice situation is not a major differentiating factor in measurement choice. This is not to say the two choice situations are the same, just that when measuring brand associations
- to more fully capture the brand associations from those in the market who do not currently buy the brand, smaller share brands, and to avoid the confound of priming or inhibition effects, prompting people for brands seems to be the better method to use. It might be argued that the measurement differences here are real differences that are important in the different choice situations. But given that most brand health metrics are hoped to be leading indicators of brand performance, a methodology that penalises at least two groups where growth is likely to be seen (nonbrand users and smaller share brands) seems a risky proposition.

\section{LIMITATIONS AND FURTHER RESEARCH}

As this research involved split sample and aggregate level analysis, it does not totally address the issue of if individuals respond to the different methods in the same way. It is also limited in scope to two markets, and further replication across a wider variety of markets would be useful to further generalise the findings.

If the choice is made to prompt for brands, then there are further questions about the composition of brand lists. What is the effect of adding or removing brands from that list on the brand associations that are elicited? This depends on the extent to which the consumer considers all other brands when eliciting an association for one. If other brands are considered, then the addition of a new brand should have an effect on the results. But if each elicitation is an independent 'is that brand linked to that attribute' then adding or removing attributes should have minimal effect on the overall results. This is an area for further research.

\section{References}

1 Keller, K. L. (2003) 'Brand synthesis: The multidimentionality of brand knowledge', Journal of Consumer Research, Vol. 29 (March), pp. 595-601.

2 Fishbein, M. and Ajzen, I. (1975) 'Belief, Attitude, Intention and Behaviour: An Introduction to Theory and Research', AddisonWesley Publishing Company, Reading, Massachusetts.

3 Woodside, A. G. and Trappey, R. J. (1992) 'Finding out why customers shop your store and buy your brand: Automatic cognitive processing models of primary choice', Journal of Advertising Research, Vol. 32, pp. 59-78. 
4 Romaniuk, J. and Sharp, B. (2004) 'Conceptualizing and measuring brand salience', Marketing Theory, Vol. 4, No. 4, pp. 327-342.

5 Barnard, N. R. and Ehrenberg, A. S. C. (1990) 'Robust measures of consumer brand beliefs', Journal of Marketing Research, Vol. 27 (November), pp. 477-484.

6 Driesener, C. and Romaniuk, J. (2001) 'Brand image? Pick a measure, any measure', in Chetty, S., Associate Professor, Collins, B., Associate Professor, (eds), ' Australian \& New Zealand Marketing Academy 2001; 2001 1-5 December', Department of Commerce, Massey University, Parmerston North.

7 Singh, S. N., Rothschild, M. L. and Churchill Jr, G. A. (1988) 'Recognition versus recall as measures of television commercial forgetting', Journal of Marketing Research, Vol. 25 (February), pp. 72-80.

8 Krugman, H. E. (1986) 'Low recall and high recognition of advertising', Journal of Advertising Research, Vol. 26 (February/ March), pp. 79-86.

9 Thorson, E. and Rothschild, M. L. (1983) 'Recognition and recall of commercials: Prediction from a text-comprehension analysis of commercial scripts', in Percy, L., Woodside, A.G. (eds), 'Advertising and Consumer Psychology', Lexington Books, Massachussets, pp. 287-302.

10 Gibson, L. D. (1994) 'Recall revisited: Recall redux — Some reactions', Journal of Advertising Research, Vol. 34, No. 3 (May/ June), pp. 107-108.

11 du Plessis, E. (1994) 'Recognition versus recall', Journal of Advertising Research, Vol. 34, No. 3 (May/June), pp. 75-91.

12 Laurent, G., Kapferer, J. -N. and Roussel, F. (1995) 'The underlying structure of brand awareness scores', Marketing Science, Vol. 14, No. 3 (Part 2), pp. G170-G179.

13 Romaniuk, J., Sharp, B., Paech, S. and Driesener, C. (2004) 'Brand and advertising awareness: Replication and extension of a known empirical generalisation', Australasian Marketing Journal, Vol. 12, No. 3, pp. 70-80.

14 Percy, L. and Rossiter, J. R. (1992) 'A model of brand awareness and brand attitude advertising strategies', Psychology and Marketing, Vol. 9, pp. 263-274.

15 Lynch Jr, J. G. and Srull, T. K. (1982) 'Memory and attentional factors in consumer choice: Concepts and research methods', Journal of Consumer Research, Vol. 9 (June), pp. 18-37.

16 Nedungadi, P. (1990) 'Recall and consumer consideration sets: Influencing choice without altering brand evaluations', Journal of Consumer Research, Vol. 17 (December), pp. 263-276.

17 Dickson, P. R. and Sawyer, A. G. (1990) 'The price knowledge and search of supermarket shoppers', Journal of Marketing, Vol. 54 (July), pp. 42-53.

18 Miller, G. A. (1956) 'The magic number seven, plus or minus two: Some limits on our capacity for processing information', The Psychological Review, Vol. 63, No. 2 (March), pp. 81-97.

19 Alba, J. W. and Chattopadhyay, A. (1986) 'Salience effects in brand recall', Journal of Marketing Research, Vol. 23, No. 4, pp. 363-369.

20 Hutchinson, J. W., Raman, K. and Mantrala, M. K. (1994) 'Finding choice alternatives in memory: Probability models of brand name recall', Journal of Marketing Research, Vol. 31 (November), pp. 441-461.

21 Bird, M., Channon, C. and Ehrenberg, A. S. C. (1970) 'Brand image and brand usage', Journal of Marketing Research, Vol. 7 (August), pp. 307-314.

22 Romaniuk, J. and Sharp, B. (2000) 'Using known patterns in image data to determine brand positioning', International Journal of Market Research, Vol. 42, No. 2 (Spring/Summer), pp. 219-230. 